Special Issue of the 8th International Advances in Applied Physics and Materials Science Congress (APMAS 2018)

\title{
The Effect of Nugget Sizes on Tensile Peel Loading in Resistance Spot Welding of DP800 and TWIP950 Steel Sheets used in Automative Industry
}

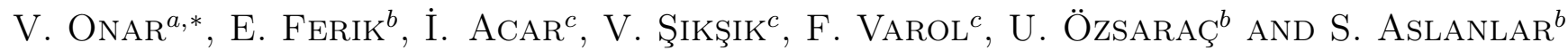 \\ ${ }^{a}$ Pamukkale University, Department of Manufacturing Engineering, Denizli, Turkey \\ ${ }^{b}$ Sakarya University, Department of Metallurgical and Materials Engineering, Sakarya, Turkey \\ ${ }^{c}$ Vocational School of Karasu, Program of Machinery and Metal Technology, Sakarya, Turkey
}

\begin{abstract}
This paper presents an experimental study on resistance spot welding of DP and TWIP steel sheets used in automative industry. A timer and current controlled resistance spot welding machine having $120 \mathrm{kVA}$ capacity and a pneumatic application mechanism with a single lever was used to prepare the specimens. Welding periods were chosen as 5, 10, 15, 20, 25 and 30 cycles $(1$ cycle $=0.02 \mathrm{~s})$ and also welding currents were increased from $6.33 \mathrm{kA}$ up to $15.7 \mathrm{kA}$ in steps of $0.9 \mathrm{kA}$. The electrode force was kept constant at $4 \mathrm{kN}$. The prepared welding specimens were exposed to tensile-peel test and micro and macro-structures of specimens were investigated by means of an optical microscope and scanning electron microscope (SEM) in order to see the joinability of DP and TWIP steel sheets by resistance spot welding. Finally appropriate welding current and time were advised to the users.
\end{abstract}

DOI: 10.12693/APhysPolA.135.1097

PACS/topics: RSW, DP800, dual phase steel, TWIP950, twinning induced plasticity steel

\section{Introduction}

Resistance spot welding (RSW) is commonly used joining technique in automotive industry due to its low cost and quick cycle time. RSW practice depends on several parameters such as the welding current, the welding cycle time, the electrode geometry, the electrode and steel materials, etc [1-4].

Twinning induced plasticity (TWIP) austenitic steels exhibit exceptional high ultimate strength and high ductility, which enables their use in the production of high performance structural parts for automotive industry and other applications [5].

Dual phase (DP) ferrite-martensite steels are multiphase grades being widely employed in automotive industry. DP steels are frequently used in body structure applications requiring high energy absorption [6].

\section{Experimental procedure}

The studied materials were DP800 steel sheets having $1.2 \mathrm{~mm}$ thicknesses and TWIP950 steel sheets having $1.4 \mathrm{~mm}$ thickness. The chemical composition and basic mechanical properties of the base materials are shown in Tables I and II, respectively.

A timer and current controlled resistance spot welding machine having $120 \mathrm{kVA}$ capacity and a pneumatic application mechanism with a single lever was used to

*corresponding author; e-mail: vonar@pau.edu.tr prepare the specimens. Welding was carried out by using water cooled conical $\mathrm{Cu}-\mathrm{Cr}-\mathrm{Zr}$ electrodes having a contact surface of $6 \mathrm{~mm}$ diameter.

TABLE I

Chemical composition [wt\%] of DP800 and TWIP950 steel sheets.

\begin{tabular}{c|c|c|c|c|c|c|c}
\hline \hline $\mathrm{C}$ & $\mathrm{Si}$ & $\mathrm{Mn}$ & $\mathrm{Al}$ & $\mathrm{Cr}$ & $\mathrm{Ti}$ & $\mathrm{W}$ & $\mathrm{V}$ \\
\hline \multicolumn{7}{c}{ DP800 steel } \\
\hline 0.147 & 0.45 & 1.93 & 0.31 & 0.256 & 0.016 & 0.135 & 0.039 \\
\hline \multicolumn{7}{c}{ TWIP950 steel } \\
\hline 0.654 & 0.039 & 17.605 & 1.712 & 0.007 & 0.06 & 0.129 & 0.004
\end{tabular}

TABLE II

Mechanical properties of DP800 and TWIP950 steel sheets.

\begin{tabular}{c|c|c}
\hline \hline Materials & DP800 & TWIP950 \\
\hline Yield strength [MPa] & 448 & 541 \\
Tensile strength [MPa] & 785 & 966 \\
Total elongation [\%] & 16.8 & 56
\end{tabular}

The welding speciments were overlapped with $30 \mathrm{~mm}$. Welding periods were chosen as $5,10,15,20,25$ and 30 cycles $(1$ cycle $=0.02 \mathrm{~s}$ ) and also welding currents were increased from $6.33 \mathrm{kA}$ up to $15.7 \mathrm{kA}$ in steps of $0.9 \mathrm{kA}$. Clamping and holding time (25 cycles) were kept constant.

All welded speciments were exposed to tensile-peel tests in a testing machine in laboratory conditions. Nugget widths $\left(d_{1}\right)$, nugget heights $\left(d_{2}\right)$ were measured and also nugget size ratios $\left(d_{2} / d_{1}\right)$ were calculated by 


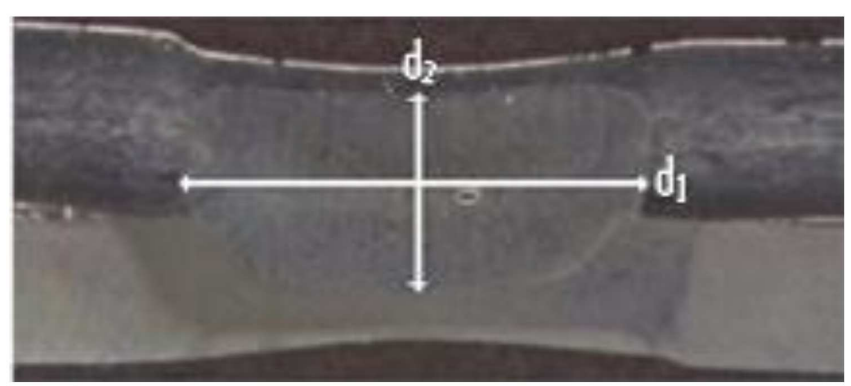

Fig. 1. Weld nugget geometry.

means of an optical microscope. Weld nugget geometry is shown in Fig. 1. The effect of welding current on nugget size was investigated by putting obtained results in related diagrams.

\section{Results and discussion}

In low welding current application, small weld nugget widths and similarly tensile-peel strength values were obtained due to low amount of heat to the welding zone and low elemental diffusion between the base metals. As a result of welding current and nugget width increments, the tensile-peel strength of welded samples rises up to 7-8 $\mathrm{mm}$ of nugget widths as shown in Fig. 2a. Tensile peel-strength of welded samples starts to decrease at nugget width above $8 \mathrm{~mm}$. When the nugget height diagram was investigated maximum tensile-peel strength of welded samples was obtained at of $0.8-1 \mathrm{~mm}$ as shown in Fig. 2b. The maximum tensile-peel strength value was obtained at nugget size ratio of $0.13-0.16$ as shown in Fig. 2c.
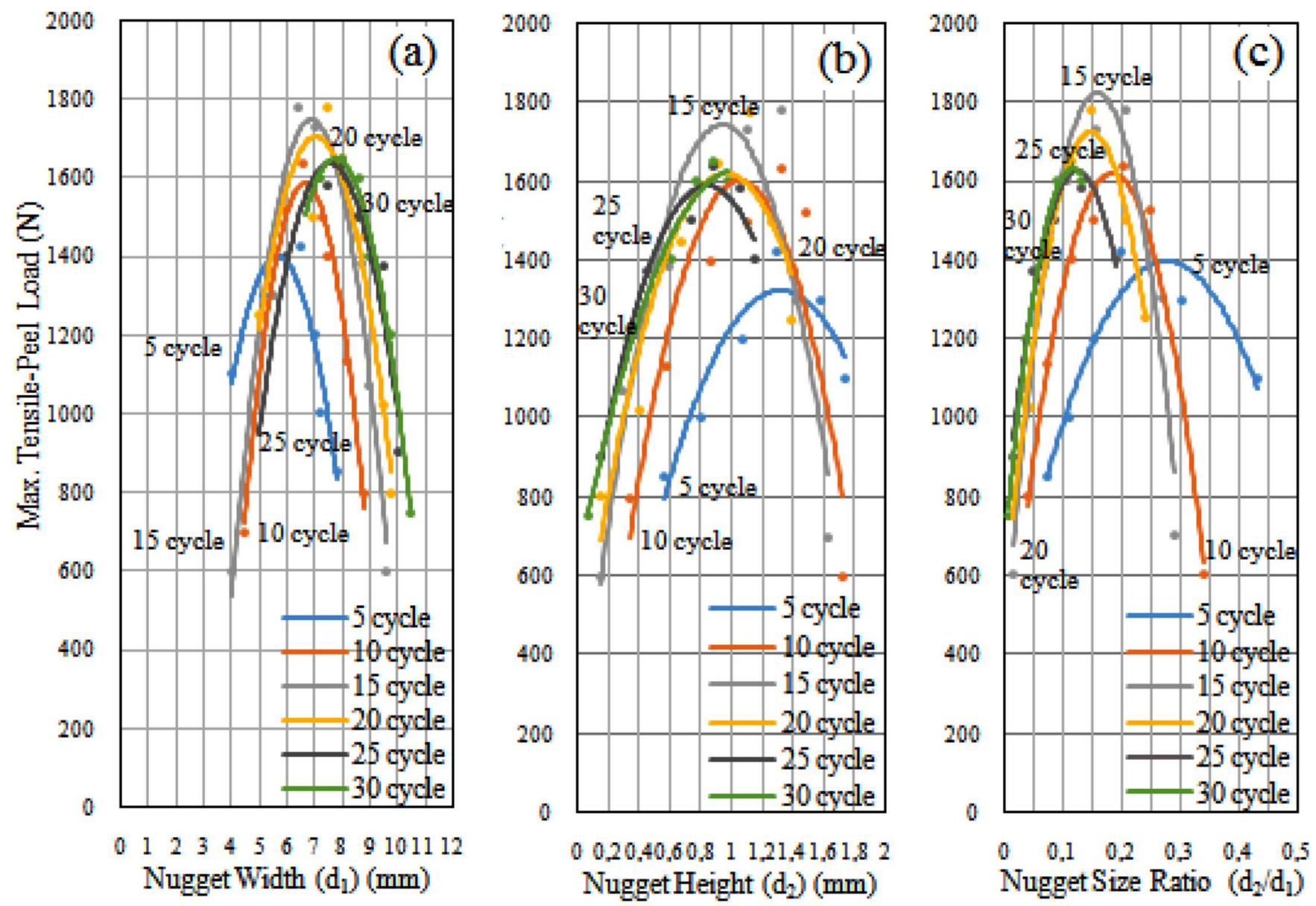

Fig. 2. The effect of nugget width (a), height (b) and size ratio (c) on tensile-peel load.

Microstructures and SEM image of interface sections are, respectively, shown in Fig. 3. DP base metal contains a combination of ferrite and martensite phase and TWIP base metal contains austenite phase. Application of electric current and pressure heats DP and TWIP steel sheets to the melting point (liquid state) of both. And a pool of molten metal that quickly cools and forms a nugget zone alloy of the two materials with larger grain growth. In Figure 3a, microstructure of DP800 and nugget zone are shown together. In Figure $3 \mathrm{~b}$, microstructure of TWIP950 and nugget zone are shown together. Figure 3c shows the electron image SEM of DP800 and nugget zone microstructure. There is an interface layer between the base metal and nugget zone. 

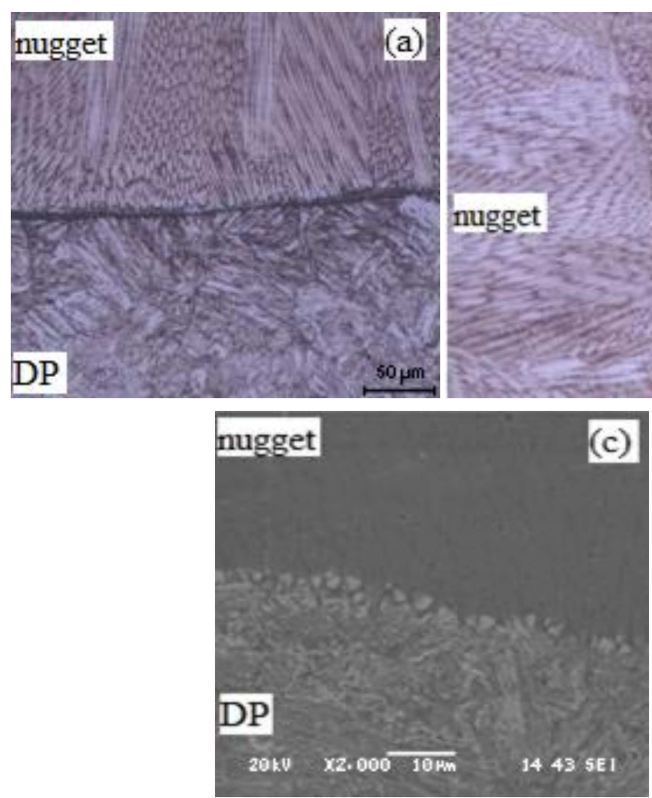

Fig. 3. Microstructure and SEM image of interface sections. (a) microstructure of DP800/nugget interface, (b) microstructure of nugget/TWIP950 interface, (c) SEM image of interface zone of DP800/nugget interface.

\section{Conclusion}

As a result of work performed at $4 \mathrm{kN}$ electrode force, maximum tensile-peel strength is obtained at $8.17 \mathrm{kA}$ welding current applied during 15 cycles. Since the depth of electrode indentation into material is not exceed the $30 \%$ of sheet thickness limit accepted for a good surface quality.

\section{References}

[1] E. Geslain, P. Rogeon, T. Pierre, C. Pouvreau, L. Cretteur, J. Mater. Process. Tech. 253, 160 (2018).

[2] V.H. Vargas, I. Mejía, V. H. Baltazar-Hernández, C. Maldonado, J. Manuf. Process. 32, 307 (2018).

[3] C. Summerville, D. Adams, P. Compston, M. Doolan, Proced. Engineer. 183, 257 (2017).

[4] Z. Miknoa, A. Pilarczyk, M. Korzeniowski, P. Kustroń, A. Ambroziak, Arch. Civil Mech. Engineer. 18, $522(2018)$.

[5] M. Madivala, A. Schwedt, S.L. Wong, F. Roters, U. Prahl, W. Bleck, Int. J. Plasticity 104, 80 (2018).

[6] H. Farivar, S. Richter, M. Hans, A. Schwedt, U. Prahl, W. Bleck, Mater. Sci. Eng. A 718, 250 (2018). 